\title{
Prevention of delayed cracking of punched 1.5 GPa ultra-high strength steel sheets by ironing with punched slug
}

\author{
Ken-ichiro Mori ${ }^{1} \cdot$ Yohei Abe $^{1} \cdot$ Yusuke Murai $^{1}$ \\ Received: 11 April 2020 / Accepted: 17 July 2020 / Published online: 2 August 2020 \\ (C) The Author(s) 2020
}

\begin{abstract}
Hydrogen-induced delayed cracking of punched $1.5 \mathrm{GPa}$ ultra-high strength steel sheets was prevented by ironing with a slug ejected from punching, because the risk of delayed cracking for sheared $1.5 \mathrm{GPa}$ sheets is very high due to high tensile residual stress and large plastic deformation. To prevent the occurrence of delayed cracking, the sheet was punched, and then, the punched hole was ironed by passing the punched slug. Although the residual stress around the punched edge of the 1.5 GPa sheet was tensile, the stress was turned to compressive stress by slug ironing. In addition, the fracture surface of the sheared edge was changed to a smooth ironed surface. A cathode hydrogen charging test of the punched edge for delayed cracking was performed. Although delayed cracks were caused at the punched hole by hydrogen charging, no cracks occurred at the ironed hole for charging. It was found that slug ironing of the punched hole is effective in preventing delayed cracking.
\end{abstract}

Keywords Delayed cracking $\cdot$ Hydrogen embrittlement $\cdot 1.5 \mathrm{GPa}$ steel $\cdot$ Punching $\cdot$ Slug ironing $\cdot$ Ultra-high strength steel sheet

\section{Introduction}

For the weight reduction and passenger safety of automobiles, the use of ultra-high strength steel sheets having a tensile strength above $1 \mathrm{GPa}$ for body-in-white parts rapidly increases [1]. The strength of the ultra-high strength steel sheets used for cold stamping attains $1.5 \mathrm{GPa}$ at present [2], and this strength is the same level as hot-stamped parts made of quenchable $22 \mathrm{MnB} 5$ steel sheets [3]. Although hot stamping is major for production of automobile $1.5 \mathrm{GPa}$ steel parts, cold stamping of the ultra-high strength steel sheets has the advantages of high productivity, conventional and cheaper equipment, no oxidation prevention treatment, etc. The drawbacks in cold stamping of the ultra-high strength steel sheets are large springback [4], large forming load, low formability [5] and short tool life [6, 7]. Won et al. [8] evaluated the stretchability of edges produced through flat blanking, humped bottom blanking, and waterjet cutting by using deep drawing and stretch flanging of ultra-high strength steel sheets. Mori et al.

Ken-ichiro Mori

mori@plast.me.tut.ac.jp

1 Department of Mechanical Engineering, Toyohashi University of Technology, Toyohashi, Aichi 441-8580, Japan
[9] indicated that the hardness for the 1.2 GPa sheet considerably approaches that of conventional $1.5 \mathrm{GPa}$ hot-stamped parts by using a warm stamping process at comparatively low temperatures with rapid resistance heating.

The risk level of hydrogen-induced delayed fracture occurring after a long time is high for the ultra-high strength steel sheets [10]. In steel sheets, the ductility generally decreases with increasing strength, and moreover, ultra-high strength steel becomes brittle due to diffusion of hydrogen $[11,12]$. The hydrogen embrittlement results in hydrogen-induced delayed fracture, and this tendency for the $1.5 \mathrm{GPa}$ sheets becomes remarkable [13]. The delayed fracture has been mostly studied in the field of ultra-high strength steel bolts and fasteners [14], because the delayed fracture is induced by a high tensile stress acting on tightened ones. Takashima et al. [15] examined the hydrogen embrittlement behavior of the ultra-high strength steel sheets under tensile loading and indicated that the tensile stress has a significant effect on the occurrence of delayed fracture. Hojo et al. [16] improved the hydrogen embrittlement of the ultrahigh strength steel sheets by adding alloying elements. Hojo et al. [17] examined the effect of strain rate on the hydrogen embrittlement of ultra-high strength TRIP (transformation induced plasticity) steel sheets. Hojo et al. [18] exhibited the relief of hydrogen embrittlement by pre-strain for ultra-high strength TRIP steel sheets. Venezuela et al. [19] examined the hydrogen embrittlement behavior of a $1.7 \mathrm{GPa}$ martensitic ultra-high 
Fig. 1 Ironing of punched hole with slug ejected from punching for preventing delayed cracking
- Tensile residual stress

- Rough surface

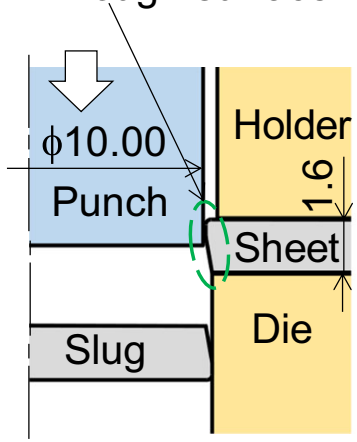

(a) 1st stage: punching
- Compressive residual stress

- Smoothed surface

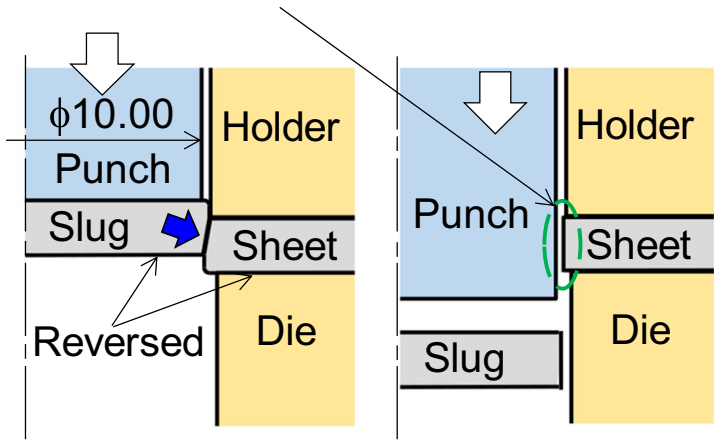

(b) 2nd stage: slug ironing strength steel sheet. For industrial application of 1.5 GPa steel sheets, it is required to prevent the occurrence of delayed fracture.

Body-in-white parts are generally punched to make many holes for joining, paint removing, attachment, reduction in weight, etc. Mori [20] reviewed shearing processes of high strength steel sheets. In punching of ultra-high strength steel sheets, the sheared edge undergoes large shear deformation, and the quality of the sheared edges deteriorates due to early onset of cracks caused for the low ductility, a large rough fracture surface [21, 22]. Moreover, a high tensile residual stress acts around the sheared edges, and the risk level of the delayed fracture rises [23]. Mori et al. [24] examined the occurrence of delayed cracking for blanked $1.5 \mathrm{GPa}$ steel sheets and showed that delayed cracking is prevented by reducing the tensile residual stress around the sheared edge. Shiozaki et al. [25] investigated the effect of the residual stress on the fatigue strength for punched high strength steel sheets. Yasutomi et al. [26] improved the fatigue strength of punched $1 \mathrm{GPa}$ sheet by reducing the residual stress by means of scrap coining.

To improve the quality of sheared edges of ultra-high strength steel sheets, Murakawa et al. [27] shaved the sheared edge. Mori et al. [28] developed a slight clearance punching process with a punch having a small round corner. In this process, not only the burnished surface of the sheared edge increases, but also the residual stress becomes compressive. Jaafar et al. [29] introduced automatic centering with a moving die into the slight clearance punching process in order to simplify setting of the punch having a small round corner and prevented the occurrence of delayed cracking for punched $1.5 \mathrm{GPa}$ sheets by the compressive residual stress. On the other hand, Mori et al. [30] ironed a hole of a punched ultra-high strength steel sheet with a taper punch in

Table 1 Mechanical properties of die-quenched 22MnB5 steel sheet

\begin{tabular}{lll}
\hline Tensile strength & Total elongation & Vickers hardness \\
\hline $1.53 \mathrm{GPa}$ & $6.8 \%$ & $480 \mathrm{VH} 1$ \\
\hline
\end{tabular}

order to smooth the sheared edge, and Kadarno et al. [31] developed a punching process including thickening around a hole with a taper punch and step die. In these punching processes, the tensile residual stress is considerably reduced by applying large shear deformation to the sheared edge under a high contact pressure, and thus, the risk level of delayed cracking becomes low.

In the present paper, hydrogen-induced delayed cracking of punched 1.5 GPa ultra-high strength steel sheets was prevented by ironing with a slug ejected from punching. The punched hole is ironed by passing the slug to reduce the tensile residual stress.

\section{Procedure of ironing of punched hole with slug for preventing delayed cracking}

In punched 1.5 GPa ultra-high strength steel sheets, the risk level of hydrogen-induced delayed fracture is very high due to high tensile residual stress and large shear deformation around the sheared edge. The delayed cracks generally appear on the rough fracture surface of the sheared edge, and the high tensile residual stress acts [24]. Although ironing of punched holes with a taper punch [30] is effective in preventing the occurrence of delayed cracking, the wear of the punch becomes remarkable because of a large slip between the punch and hole under a high contact pressure. Therefore, an ironing process without an ironing punch is developed.

Table 2 Conditions of punching and slug ironing

\begin{tabular}{ll}
\hline Punch diameter & $10.00 \mathrm{~mm}$ \\
Ratio of clearance for punching & $c=10$ and 20\% \\
Punch and die & SKD11 \\
Sheet thickness & $1.6 \mathrm{~mm}$ \\
Sheet length & $40 \mathrm{~mm}$ \\
Punching speed & $200 \mathrm{~mm} / \mathrm{s}$ \\
\hline
\end{tabular}




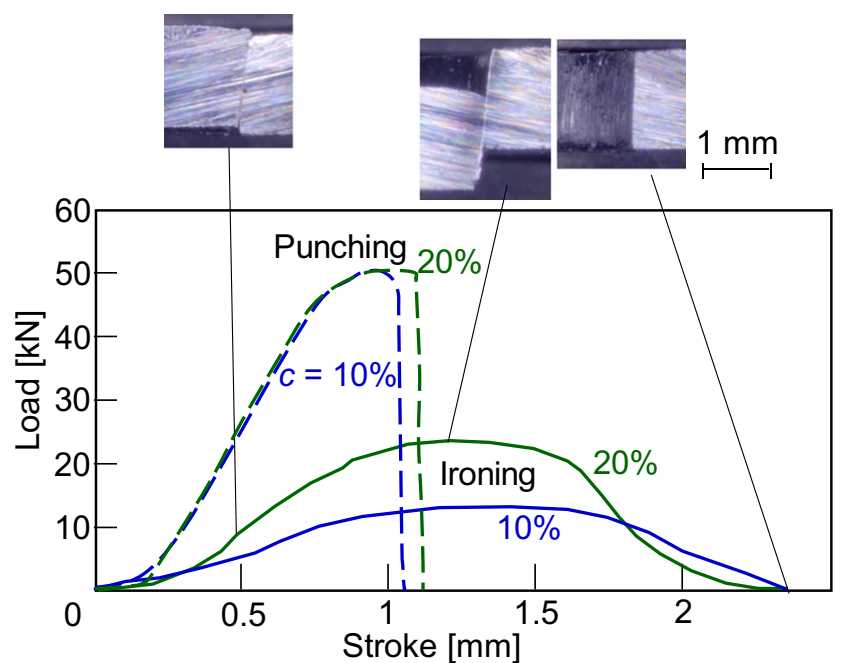

Fig. 2 Punching and ironing load-stroke curves for $c=10$ and $20 \%$

A process for preventing delayed cracking in punching of $1.5 \mathrm{GPa}$ ultra-high strength steel sheets is proposed in this study. In this process, a slug ejected as a scrap from punching is employed to iron the punched hole, as shown in Fig. 1. The 1.5 GPa ultra-high strength steel sheet is punched in the first stage; then, the sheet and slug are turned upside down, and the punched hole is ironed by passing the slug in the second stage. Since both fracture surfaces of the hole and slug are inclined by the clearance between the die and punch in punching, the punched hole is ironed with the slug, and the hole surface is smoothed by the large shear deformation under a high contact pressure. By the large shear deformation during slug ironing, the high tensile residual stress around the sheared edge induced by punching is tuned to a compressive stress. The compressive residual stress and the smoothed surface lead to the prevention of delayed cracking occurring at the sheared edge [24]. This process using a discarded slug is economical.

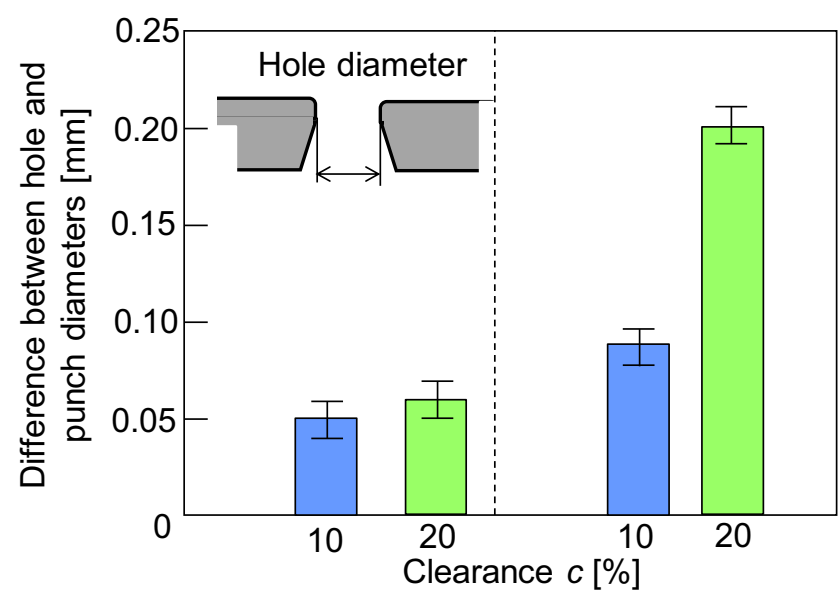

(a) Punching

(b) Slug ironing

Fig. 4 Diameters of punched and ironed holes for $c=10$ and $20 \%$

The steel sheet used for punching and ironing was made of a die-quenched 22MnB5 steel sheet having $1.6 \mathrm{~mm}$ in thickness. The die-quenched 22MnB5 (C: $0.21 \%$, Si: $0.25 \%$, Mn: 1.2\%, P: $0.015 \%$, B: $0.0014 \%$ ) was martensite steel and had similar mechanical properties to commercial $1.5 \mathrm{GPa}$ ultra-high strength steel sheets used for cold stamping. The Al-Si-coated 22MnB5 sheet was heated to $910{ }^{\circ} \mathrm{C}$ in an electric furnace, and then was die-quenched by being sandwiched between two thick steel plates under a pressure of $30 \mathrm{MPa}$ for $30 \mathrm{~s}$. The mechanical properties of the sheet measured from the uniaxial tensile and hardness tests are given in Table 1.

The conditions of punching and slug ironing are shown in Table 2. The ratio of the clearance between the punch and die to the sheet thickness for punching was $c=10$ and $20 \%$, where the punch diameter was fixed to $10.00 \mathrm{~mm}$ and the hole diameter of the die was changed for the clearance ratio. A clearance ratio of $10 \%$ is commonly employed for punching and a larger ratio of $20 \%$ is added. The die and punch used for slug ironing were the same as those for punching. The punches and dies
Fig. 3 Surfaces and crosssections of punched and ironed edges for $c=10$ and $20 \%$
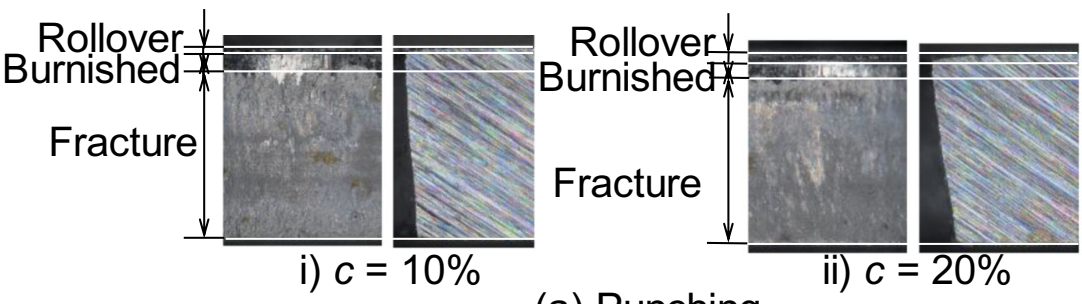

(a) Punching

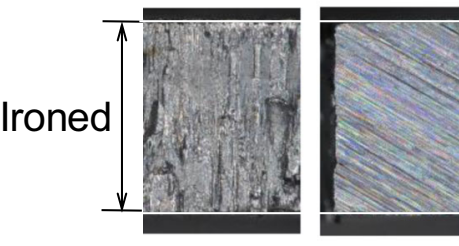

i) $c=10 \%$

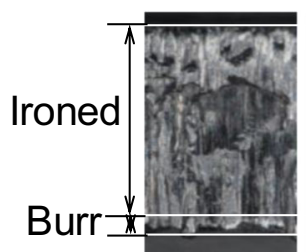

ii) $c=20 \%$

(b) Slug ironing

$1 \mathrm{~mm}$ 
Fig. 5 Distributions of residual stress in thickness direction at punched edge for $c=10$ and $20 \%$

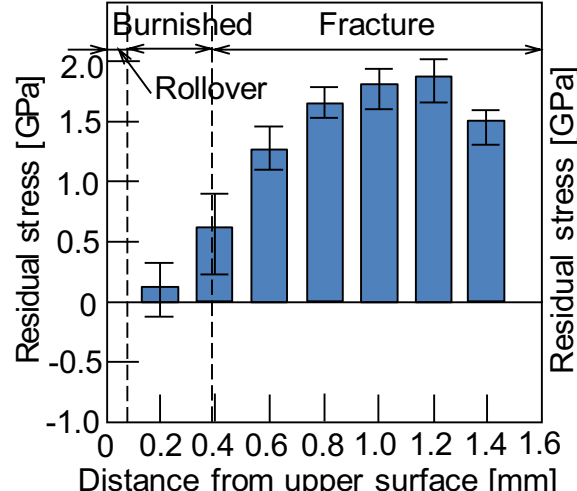

(a) $c=10 \%$

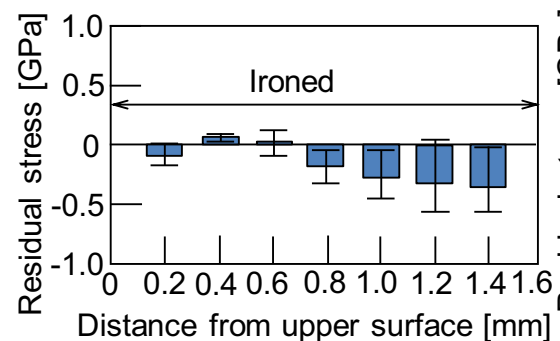

(a) $c=10 \%$

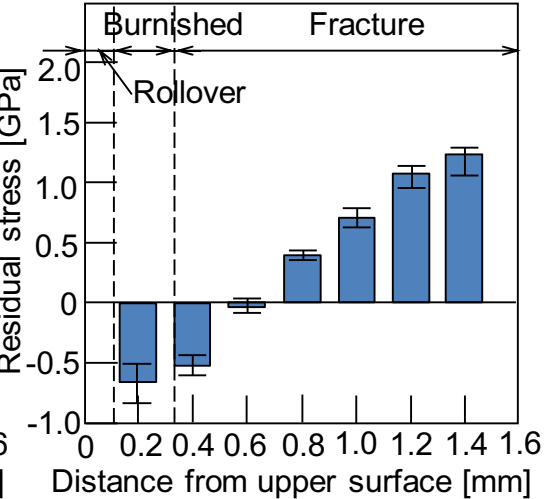

(b) $c=20 \%$
Fig. 6 Distributions of residual stress in thickness direction at ironed edges for $c=10$ and $20 \%$

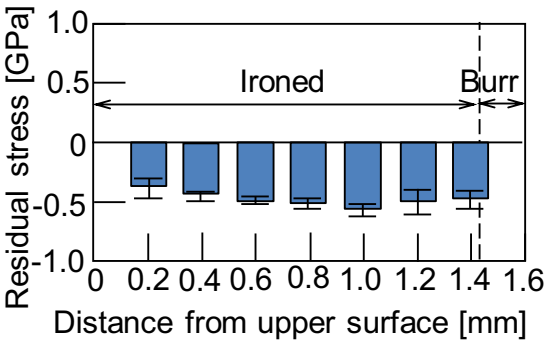

(b) $c=20 \%$ were made of the die steel SKD11, and no lubricant was applied at the tool-sheet interfaces. The sheet having a thickness of $1.6 \mathrm{~mm}$ was a square having $40 \mathrm{~mm}$ in length, and the middle of the sheet was punched and ironed. Since steel sheets are conventionally punched at a high punching speed in industry, a punching speed of $200 \mathrm{~mm} / \mathrm{s}$ was chosen.

\section{Results of punching and slug ironing}

The punching and ironing load-stroke curves for $c=10$ and $20 \%$ are shown in Fig. 2. Although the punching loads for $c=$ 10 and $20 \%$ are similar, the ironing load for $c=20 \%$ is higher due to increase in amount of ironing. The ironing load is considerably lower than the punching load, whereas the stroke

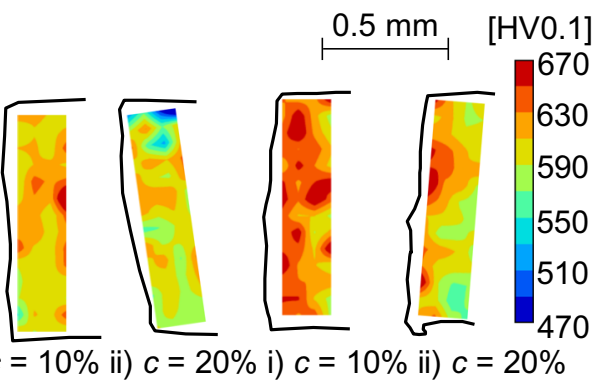
(a) Punching
(b) Slug ironing

Fig. 7 Distributions of Vickers hardness in vicinity of punched and ironed edges for $c=10$ and $20 \%$ for ironing is long. The punching load sharply drops after attaining the peak load due to the rapid progress of cracks.

The surfaces and cross-sections of the punched and ironed edges for $c=10$ and $20 \%$ are illustrated Fig. 3. The surfaces and cross-sections of the ironed edges are upside down from those of the punched edges, because the punched sheet and the slug are turned for slug ironing after punching. The burnished and fracture surfaces of the punched edge are small and large, respectively, due to low ductility. The large fracture surface is ironed into the smooth surface with the slug. The slope of the fracture surface of the punched edge for $c=20 \%$ is larger, and thus, the amount of slug ironing increases. For $c=10 \%$, the whole surface of the ironed edge is smooth, whereas the burr is caused by excessive ironing for $c=20 \%$. Punching for $\mathrm{c}=$ $10 \%$ is sufficient for slug ironing. It was found that the surface quality of the hole is improved by slug ironing.

The diameters of the punched and ironed holes measured by a vernier caliper for $c=10$ and $20 \%$ are illustrated in Fig. 4 . The ironed holes are expanded from the punched holes by slug ironing, and the hole diameter for $c=20 \%$ is larger due to the increase in amount of ironing.

The distributions of residual stress in the thickness direction at the punched edges for $c=10$ and 20\% are shown in Fig. 5. The residual stress was measured with the X-ray diffraction technique using the $\cos \alpha$ method [32] without cutting, and the diameter of the measuring spot was about $0.4 \mathrm{~mm}$. The X-ray cannot be applied in the hoop direction of the hole, and the residual stress 


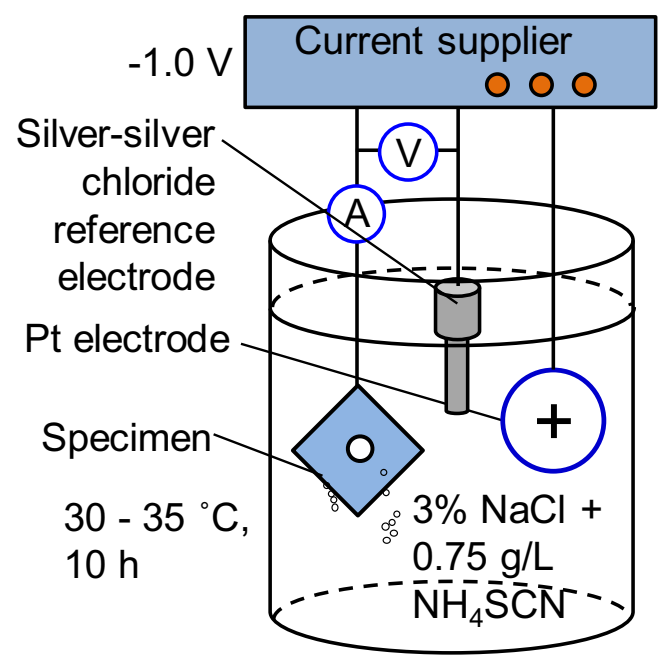

Fig. 8 Cathode hydrogen charging test of punched and ironed holes for delayed cracking

only in the thickness direction was measured. The residual stress increases from the upper surface and has the highest peak on the fracture surface. Since the burnished surface is generated by shear deformation under the contact with the punch, the residual stress is low. On the other hand, the residual stress on the fracture surface is high due to the progress of cracks without contact with tools. The residual stress for $c=10 \%$ is higher than that for $c=$ $20 \%$ and exceeds $1.5 \mathrm{GPa}$ due to the tensile residual stress in the hoop direction. In $c=10 \%$ conventionally used for punching operations, the tensile residual stress for the punched 1.5 GPa sheet becomes considerably high. Such a high tensile residual stress on the fracture surface results delayed cracking.
The distributions of residual stress in the thickness direction at the ironed edges for $c=10$ and $20 \%$ are shown in Fig. 6. The tensile residual stress at the punched edge is turned to the compressive stress by slug ironing. The compressive residual stress is induced by large shear deformation under a high contact pressure during ironing.

The distributions of Vickers hardness in the vicinity of the punched and ironed edges for $c=10$ and $20 \%$ are shown in Fig. 7. The Vickers hardness around the hole edge is increased by slug ironing, and the hardness around the ironed edge for $c=10 \%$ is larger than that for $c=20 \%$.

\section{Results of delayed cracking}

A cathode hydrogen charging test of the punched and ironed holes for delayed cracking [33] was performed, as shown in Fig. 8. The specimen was held in the $3 \% \mathrm{NaCl}+0.75 \mathrm{~g} / \mathrm{L}$ NH4SCN aqueous solution kept between 30 and $35^{\circ} \mathrm{C}$ with the silver-silver chloride reference electrode for a potential of $-1.0 \mathrm{~V}$ for $10 \mathrm{~h}$. The occurrence of cracks at the hole edges was observed with the naked eye, and no cracks appeared at all hole edges just before hydrogen charging. This test is that for accelerating hydrogen charging for delayed cracking.

The surfaces of the punched and ironed edges after $10 \mathrm{~h}$ hydrogen charging are illustrated in Fig. 9. Although cracks appear at the punched edge, no cracks occur at the ironed edge. The cracks at the punched edge were initiated on the fracture surface along the hoop
Fig. 9 Surfaces of punched and ironed edges after $10 \mathrm{~h}$ hydrogen charging
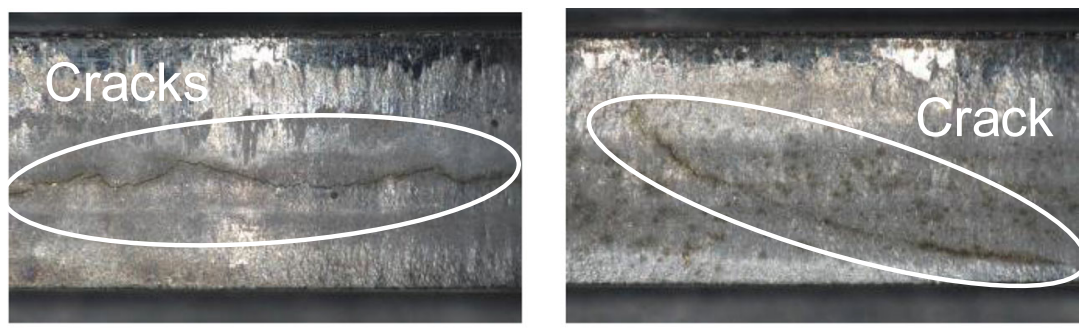

i) $c=10 \%$

(a) Punching

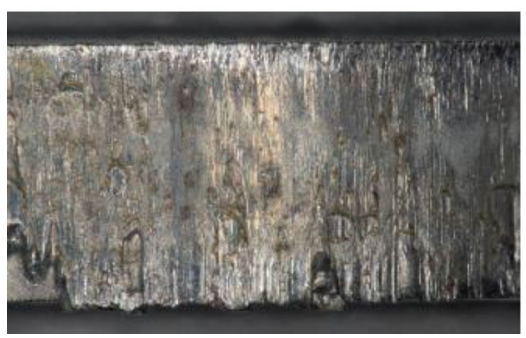

i) $c=10 \%$

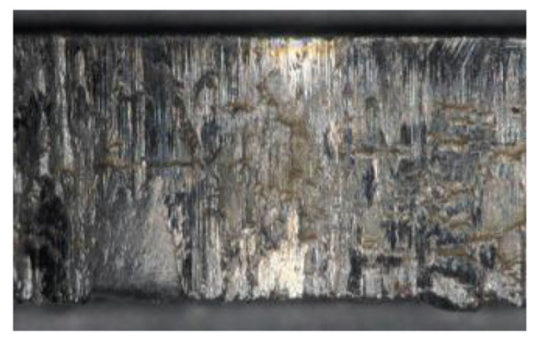

ii) $c=20 \%$

(b) Slug ironing

$1 \mathrm{~mm}$ 
Fig. 10 Combination of punching and slug ironing processes into one stage

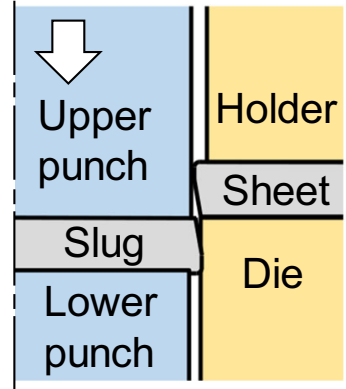

(a) Punching

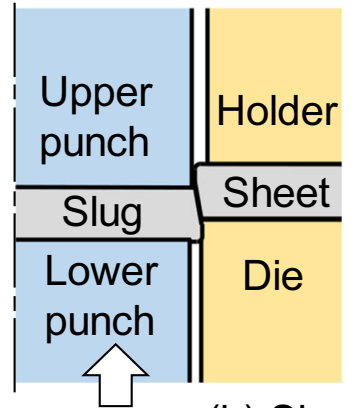

(b) Slug ironing

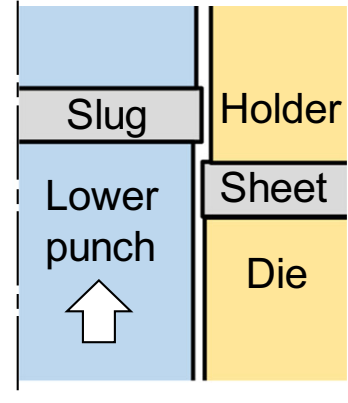

Die
Fig. 11 Surfaces and crosssections of ironed edges for one stage

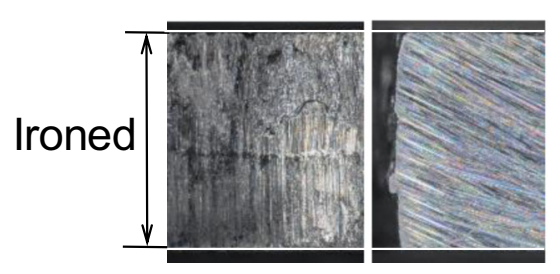

(a) $c=10 \%$

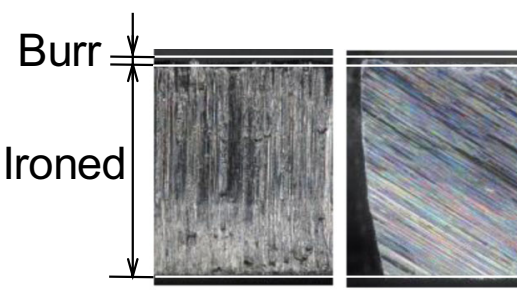

(b) $c=20 \%$
$1 \mathrm{~mm}$

direction by the tensile residual stress shown in Fig. 6, and the cracks were prevented by the compressive residual stress in spite of the increase in hardness by ironing shown in Fig. 7. Although delayed cracking induced by punching is surface cracking, the cracks gradually progress under loading and cause severe damage to parts. Although the embrittlement occurs for hydrogen charging, delayed cracking is caused by the addition of the tensile residual stress to the embrittled steel. Not only the tensile residual stress is eliminated by slug ironing, but also the fracture surface is smoothed. It was found that the elimination of the tensile residual stress by slug ironing is greatly effective in preventing the occurrence of delayed cracking, and punching for a clearance ratio of about $10 \%$ and slug ironing are useful in preventing delayed cracking of the $1.5 \mathrm{GPa}$ steel sheets without a burr.

Fig. 12 Distributions of residual stresses in thickness directions at ironed edges for one stage

\section{Combination of punching and slug ironing processes into one stage}

Since it is not easy to turn the sheet and slug upside down in a sequence of actual stamping operations, the punching and slug ironing processes are combined into one stage, as shown in Fig. 10. The transfer of the ejected slug to the next stage is also omitted. The sheet is punched with the upper punch, and then, the slug is pushed back to the hole with the lower punch. The lower punch is driven by a die cushion of the press due to the low slug ironing load shown in Fig. 2.

The surfaces and cross-sections of the ironed edges for the one stage are illustrated in Fig. 11. The surfaces and crosssections are almost similar to those turning upside down for the two stages shown in Fig. 3b. The burr appears due to excessive ironing for $c=20 \%$.

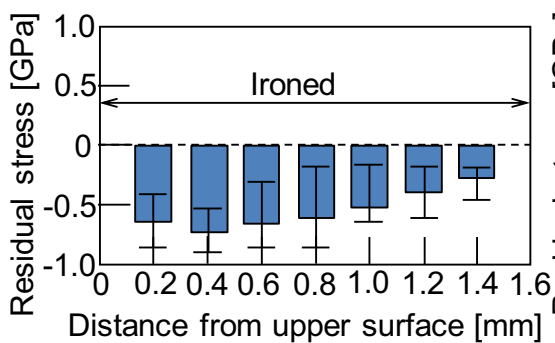

(a) $c=10 \%$

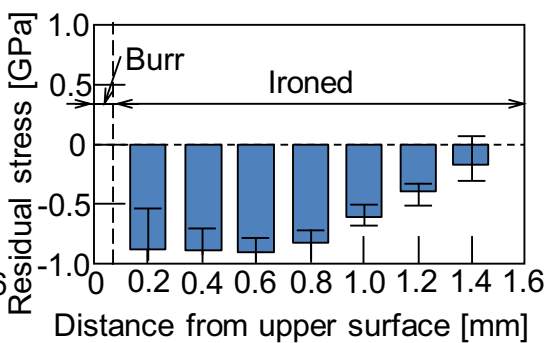

(b) $c=20 \%$ 
Fig. 13 Surfaces of ironed edges after 10-h hydrogen charging for one stage

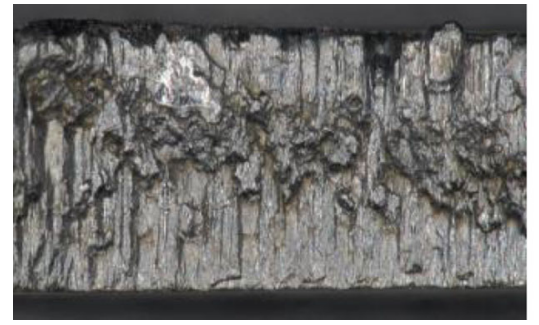

i) $c=10 \%$

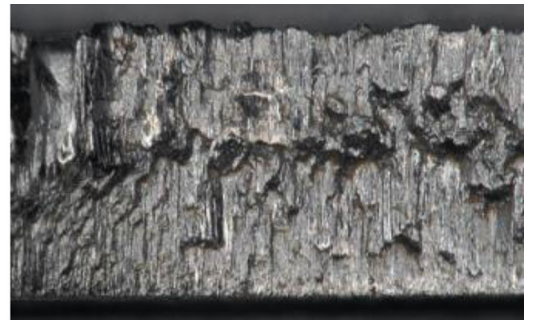

ii) $c=20 \%$
The distributions of residual stress in the thickness direction at the ironed edges for one stage are shown in Fig. 12. The tensile residual stress at the punched edge is turned to the compressive stress by slug ironing as well as that for the two stages shown in Fig. 6.

The surfaces of the ironed edges after 10-h hydrogen charging for the one stage are illustrated Fig. 13. No cracking occurred as well as the two stages because of the compressive residual stress shown in Fig. 12. The combined punching and slug ironing can be applied to a sequence of actual stamping operations. It was found that the combined punching and slug ironing for $c=10 \%$ are enough to prevent delayed cracking without a burr.

\section{Conclusions}

The application of cold stamping of 1.5 GPa ultra-high strength steel sheets to automotive body-in-white has started. The conventional $1.5 \mathrm{GPa}$ sheets have a serious problem of hydrogen embrittlement, and not only the mechanical properties of formed parts such as strength, ductility, and toughness decrease, but also the delayed fracture occurs. Approaches of material development such as the addition of alloying elements and microstructure control for heightening the hydrogen embrittlement resistance are developing. The tensile residual stress and plastic deformation around sheared edges induced by shearing processes such as blanking, punching, and trimming are higher than those by forming processes, and the risk level of delayed cracking at the sheared edges is higher. For the industrial application of the $1.5 \mathrm{GPa}$ sheets, it is essential to reduce the residual stress at the sheared edges.

In the present study, delayed cracking of punched $1.5 \mathrm{GPa}$ ultra-high strength steel sheets was prevented by ironing with punched slug, and the obtained results are summarized as follows:

(1) The punched hole was ironed with a slug ejected as a scrap from punching.

(2) The tensile residual stress at the punched edge was eliminated by slug ironing.
(3) Delayed cracking was prevented by the compressive residual stress and the smoothed surface.

(4) The punching and slug ironing processes are combined using a counter punch into one stage not to turn the sheet and slug upside down.

(5) Punching for a clearance ratio of about $10 \%$ and slug ironing are useful in preventing delayed cracking of the $1.5 \mathrm{GPa}$ steel sheets without a burr.

The present slug ironing process is effective in eliminating the tensile residual stress at the sheared edges as well as the improvement of the surface quality, and thus, the occurrence of delayed cracking is prevented by ironing. Large shear deformation is applied under a high contact pressure to the sheared edges by slug ironing. The combined punching and slug ironing processes into one stage render the application of this process to a sequence of actual stamping operations comparatively easy. It, however, is required to deal with the slug upward ejected by ironing. The present process is also useful for improving the fatigue strength because of the compressive residual stress around the hole edge.

Acknowledgments This paper is based on results obtained from a project commissioned by the New Energy and Industrial Technology Development Organization (NEDO).

Open Access This article is licensed under a Creative Commons Attribution 4.0 International License, which permits use, sharing, adaptation, distribution and reproduction in any medium or format, as long as you give appropriate credit to the original author(s) and the source, provide a link to the Creative Commons licence, and indicate if changes were made. The images or other third party material in this article are included in the article's Creative Commons licence, unless indicated otherwise in a credit line to the material. If material is not included in the article's Creative Commons licence and your intended use is not permitted by statutory regulation or exceeds the permitted use, you will need to obtain permission directly from the copyright holder. To view a copy of this licence, visit http://creativecommons.org/licenses/by/4.0/.

\section{References}

1. Tisza M, Czinege I (2018) Comparative study of the application of steels and aluminium in lightweight production of automotive parts. Int J Lightweight Mater Manuf 1(4):229-238. https://doi.org/10. 1016/j.ijlmm.2018.09.001 
2. Kalpakjian S, Schmid SR (2014) Manufacturing engineering and technology, 7th edn. Pearson, pp 139-142

3. Mori K, Bariani PF, Behrens BA, Brosius A, Bruschi S, Maeno T, Merklein M, Yanagimoto J (2017) Hot stamping of ultra-high strength steel parts. CIRP Ann Manuf Technol 66(2):755-777. https://doi.org/10.1016/j.cirp.2017.05.007

4. Mori K, Akita K, Abe Y (2007) Springback behaviour in bending of ultra-high-strength steel sheets using $\mathrm{CNC}$ servo press. Int $\mathrm{J}$ Mach Tool Manu 47(2):321-325. https://doi.org/10.1016/j. ijmachtools.2006.03.013

5. Kaupper M, Merklein M (2013) Bendability of advanced high strength steels - a new evaluation procedure. CIRP Ann Manuf Technol 62(1):247-250. https://doi.org/10.1016/j.cirp.2013.03.049

6. Kim H, Han S, Yan Q, Altan T (2008) Evaluation of tool materials, coatings and lubricants in forming galvanized advanced high strength steels (AHSS). CIRP Ann Manuf Technol 57(1):299304. https://doi.org/10.1016/j.cirp.2008.03.029

7. Li H, Wu X, Li G, Zhou D (2020) Chipping damage of die for trimming advanced high-strength steel sheet: evaluation and analysis. J Mater Process Technol 285:116787. https://doi.org/10.1016/j. jmatprotec.2020.116787

8. Won C, Lee W, Lee H, Kang Y, Yoon J (2020) Evaluation of inplane edge stretchability under severe contact condition for thirdgeneration advanced high-strength steel. Int J Adv Manuf Technol 108:1945-1958. https://doi.org/10.1007/s00170-020-05537-x

9. Mori K, Abe Y, Miyazawa S (2020) Warm stamping of ultra-high strength steel sheets at comparatively low temperatures using rapid resistance heating. Int J Adv Manuf Technol 108(11-12):38853891. https://doi.org/10.1007/s00170-020-05642-x

10. Takagi S, Toji Y, Yoshino M, Hasegawa K (2012) A hydrogen embrittlement resistance evaluation of ultra high strength steel sheets for automobiles. ISIJ Int 52(2):316-322. https://doi.org/10. 2355/isijinternational.52.316

11. Lee SJ, Ronevich JA, Krauss G, Matlock DK (2010) Hydrogen embrittlement of hardened low-carbon sheet steel. ISIJ Int 50(2): 294-301. https://doi.org/10.2355/isijinternational.50.294

12. Liu Q, Zhou Q, Venezuela J, Zhang M, Atrens A (2017) Hydrogen influence on some advanced high-strength steels. Corros Sci 125: 114-138. https://doi.org/10.1016/j.corsci.2017.06.012

13. Venezuela J, Zhou Q, Liu Q, Li H, Zhang M, Dargusch MS, Atrens A (2018) The influence of microstructure on the hydrogen embrittlement susceptibility of martensitic advanced high strength steels. Mater Today Commun 17:1-14. https://doi.org/10.1016/j. mtcomm.2018.07.011

14. Kuduzović A, Poletti MC, Sommitsch C, Domankova M, Mitsche S, Kienreich R (2014) Investigations into the delayed fracture susceptibility of 34CrNiMo6 steel, and the opportunities for its application in ultra-high-strength bolts and fasteners. Mater Sci Eng A 590:66-73. https://doi.org/10.1016/j.msea.2013.10.019

15. Takashima K, Yoshioka Y, Yokoyama K, Funakawa Y (2018) Hydrogen embrittlement behavior of ultra-high strength dual phase steel sheet under sustained tensile-loading test. ISIJ Int 58(1):173178. https://doi.org/10.2355/isijinternational.ISIJINT-2017-315

16. Hojo T, Kobayashi J, Sugimoto K, Nagasaka A, Akiyama E (2020) Effects of alloying elements addition on delayed fracture properties of ultra high-strength trip-aided martensitic steels. Metals 10(1):6. https://doi.org/10.3390/met10010006

17. Hojo H, Kikuchi R, Waki H, Nishimura F, Ukai Y, Akiyama E (2018) Effect of strain rate on the hydrogen embrittlement property of ultra high-strength low alloy TRIP-aided steel. ISIJ Int 58(4): 751-759. https://doi.org/10.2355/isijinternational.ISIJINT-2017576

18. Hojo H, Kumai B, Koyama M, Akiyama E, Waki H, Saitoh H, Shiro A, Yasuda R, Shobu T, Nagasaka A (2020) Hydrogen embrittlement resistance of pre-strained ultra-high-strength low alloy
TRIP-aided steel. Int J Fract 224:253-260. https://doi.org/10.1007/ s10704-020-00451-5

19. Venezuela J, Lim FY, Liu L, James S, Zhou Q, Knibbe R, Zhang M, Li H, Dong F, Dargusch MS, Atrens A (2020) Hydrogen embrittlement of an automotive $1700 \mathrm{MPa}$ martensitic advanced highstrength steel. Corros Sci 171:108726. https://doi.org/10.1016/j. corsci.2020.108726

20. Mori K (2020) Review of shearing processes of high strength steel sheets. J Manuf Mater Process 4(2):54. https://doi.org/10.3390/ jmmp4020054

21. So H, Faßmann D, Hoffmann H, Golle R, Schaper M (2012) An investigation of the blanking process of the quenchable boron alloyed steel $22 \mathrm{MnB} 5$ before and after hot stamping process. J Mater Process Technol 212(2):437-449. https://doi.org/10.1016/j. jmatprotec.2011.10.006

22. Chumrum P, Koga N, Premanond V (2015) Experimental investigation of energy and punch wear in piercing of advanced highstrength steel sheet. Int J Adv Manuf Technol 79:1035-1042. https://doi.org/10.1007/s00170-015-6902-z

23. Yoshino M, Ohji Y, Takagi S, Hasegawa K (2014) Influence of sheared edge on hydrogen embrittlement resistance in an ultra-high strength steel sheet. ISIJ Int 54(6):1416-1425. https://doi.org/10. 2355/isijinternational.54.1416

24. Mori K, Abe Y, Sedoguchi K (2019) Delayed fracture in cold blanking of ultra-high strength steel sheets. CIRP Ann Manuf Technol 68(1):297-300. https://doi.org/10.1016/j.cirp.2019.04.111

25. Shiozaki T, Tamai Y, Urabe T (2015) Effect of residual stresses on fatigue strength of high strength steel sheets with punched holes. Int J Fatigue 80:324-331. https://doi.org/10.1016/j.ijfatigue.2015.06. 018

26. Yasutomi T, Yonemura S, Yoshida T, Mizumura M, Hiwatashi S (2017) Blanking method with aid of scrap to reduce tensile residual stress on sheared edge. J Phys Conf Ser 896:012098. https://doi.org/ 10.1088/1742-6596/896/1/012098

27. Murakawa M, Suzuki M, Shionome T, Komuro F, Harai A, Matsumoto R, Koga N (2014) Precision piercing and blanking of ultrahigh-strength steel sheets. Procedia Eng 81:1114-1120. https://doi.org/10.1016/j.proeng.2014.10.219

28. Mori K, Abe Y, Kidoma Y, Kadarno P (2013) Slight clearance punching of ultra-high strength steel sheets using punch having small round edge. Int J Mach Tool Manu 65:41-46. https://doi. org/10.1016/j.ijmachtools.2012.09.005

29. Jaafar H, Mori K, Abe Y, Nakanishi K (2016) Automatic centring with moving die for cold small clearance punching of die-quenched steel sheets. J Mater Process Technol 227:190-199. https://doi.org/ 10.1016/j.jmatprotec.2015.08.010

30. Mori K, Abe Y, Suzui Y (2010) Improvement of stretch flangeability of ultra high strength steel sheet by smoothing of sheared edge. J Mater Process Technol 210(4):653-659. https:// doi.org/10.1016/j.jmatprotec.2009.11.014

31. Kadarno P, Mori K, Abe Y, Abe T (2014) Punching process including thickening of hole edge for improvement of fatigue strength of ultra-high strength steel sheet. Manu Rev 1(4):1-12. https://doi. org $/ 10.1051 / \mathrm{mfreview} / 2014003$

32. Lin J, Ma N, Lei Y, Murakawa H (2017) Measurement of residual stress in arc welded lap joints by $\cos \alpha \mathrm{X}$-ray diffraction method. J Mater Process Technol 243:387-394. https://doi.org/10.1016/j. jmatprotec.2016.12.021

33. Takagi S, Toji Y (2012) Application of NH4SCN aqueous solution to hydrogen embrittlement resistance evaluation of ultra-high strength steels. ISIJ Int 52(2):329-331. https://doi.org/10.2355/ isijinternational.52.329

Publisher's note Springer Nature remains neutral with regard to jurisdictional claims in published maps and institutional affiliations. 